\title{
Correction to: Bedform evolution and dynamics of a geostrophic current-swept shelf, northern KwaZulu-Natal, South Africa
}

\author{
A. N. Green ${ }^{1,2} \cdot$ B. W. Flemming ${ }^{3} \cdot$ J. A. G. Cooper ${ }^{1,2} \cdot$ T. F. Wanda $^{1}$
}

Published online: 19 January 2022

๑) Springer-Verlag GmbH Germany, part of Springer Nature 2022

Correction to: Geo-Marine Letters (2022) 42:1

https://doi.org/10.1007/s00367-021-00722-7

The originally published version of this article contains an incorrect copyright. The correct copyright is shown above.

The original article has been corrected.

Publisher's note Springer Nature remains neutral with regard to jurisdictional claims in published maps and institutional affiliations.

The original article can be found online at https://doi.org/10.1007/ s00367-021-00722-7.

A. N. Green

greena1@ukzn.ac.za

1 School of Agricultural, Earth and Environmental Sciences, University of KwaZulu-Natal, Durban, South Africa

2 School of Environmental Sciences, University of Ulster, Coleraine BT52 1SA, UK

3 Abteilung Meeresforschung, Senckenberg Gesellschaft Für Naturforschung, Suedstrand 40, 26318 Wilhelmshaven, Germany 